\title{
Economic Analysis of the Multiple Effects of Single Market to Pricing Policy for Meat in Iraq
}

\author{
Norsida Man $^{[\mathrm{a}]}$; Sarmad Ali Hussein $^{[\mathrm{b}]}$; Ismail Latif $^{[\mathrm{c}]}$; NittyHirawaty $^{[\mathrm{d}]}$ \\ [a] Prof. (PhD), Department of Agribusiness and Information System (Agricultural Economics), Universiti \\ Putra Malaysia, 43400 UPM Serdang, Selangor, Malaysia. \\ [b] Student (PhD), Department of Agribusiness and Information System (Agricultural Economics), Universiti \\ Putra Malaysia,43400 UPM Serdang,Selangor, Malaysia. Assoc. Prof. Al-Furat Al-Awsat Technical \\ UniversityVraq. \\ [c] Assoc Prof, Head of Department (PhD), Department of Agribusiness and Information System (Agricultural \\ Economics), Universiti Putra Malaysia,43400 UPM Serdang,Selangor, Malaysia. \\ [d] Assoc. Prof. (PhD), Department of Agribusiness and Information System (Agricultural Economics), \\ Universiti Putra Malaysia,43400UPMSerdang,Selangor, Malaysia.
}

\begin{abstract}
This study is an attempt to measure the multiple effects of the price system used in some types of meat in Iraq (fish and beef). Effects quantitatively representative of state revenue and the efficiency of production and consumption and its impact on economic performance efficiency as well as the producer and consumer surplus. Projects supported by the state and livestock production. For the purpose of increasing production. After that the demand has increased to a large extent on animal products. As well as the disclosure of the negative effects that occurs from the use of price policy. Mathematics standards use in data analysis and obtaining results. The results include revenues increased state support for low beef and projects for those revenues to support fish projects. There is a loss of production and consumption, efficient use of resources of the two commodities studied in addition to the loss in the efficient use of resources at the level of the economy as a whole. We find that the price of the policy of encouraging the producers of beef, as it was not for the benefit of consumers significantly. As for the fish was not a specific policy to protect the pair to producers or consumers volatile favor producers in some years and in favor of consumers through more than a year. You should reconsider some of the negative aspects of the pricing policy for the advancement of animal production sector.
\end{abstract}

Keywords: Meat products; Pricing Policy; PartialEquilibrium; Iraq.

\section{Introduction}

Agricultural price policy raised the prices of agricultural products significantly. The state is working on the price of a system designed to stimulate producers by increasing the purchase prices of their products for the purpose of increasing the production and provision of goods and increase the well-being of producers. On the other hand, the state has worked to increase the amount of animal products in the domestic market at reasonable prices for consumers, especially after the establishment of a national program for the rehabilitation of animal products in 1998. In addition to supporting the prices of food commodities. All of these measures to create incentives encouraging consumers and increase well-being. Implementation of these policies need to be a financial burden on the treasury, whether local or foreign currency, so the price of the policy affects the wellbeing of both producers and consumers procedures, as well as the impact on state revenues from the local currency or foreign currency when importing as well as its impact on the country's economic performance. This search measure and analyze multiple economic effects of the prices of some of the policies of meat products in Iraq. We will focus on fish meat, beef, which are important food commodities, and increased demand in recent years. The theoretical framework includes to illustrate the economic effects resulting from policy analysis to support prices and the balance is full of my market effects and move one and the impact of support. The practical side by measuring and analyzing the economic impact of goods during the period studied (1985-2013).

\section{Problem Statement}

State supported animal production projects, the prices of production inputs, especially for the purpose of increasing production after 1997. After that the demand has increased to a large extent on animal products. However, there were negative effects of the pricing policy pursued by the state. So the study was to measure the multiple effects of the price system used and the discovery of the negative effects of each goods.

\section{Objective of research}

This study attempts to uncover the multiple economic effects within the specimen single market price system used in some types of meat in Iraq (fish and beef) those effects represented quantitatively from state 
revenue, production and consumption efficiency and its impact on the efficiency of economic performance, a surplus of producers and consumers.

\section{Research methods}

Search data collection research on secondary data sources adopted which is a time series for the period (1985-2013) from the official bodies such as the Ministry of Planning, National Accounts Department and the Department of Agriculture statistics. In addition to research and published studies and theses in the field of this study. The analysis method was adopted to use mathematical models to measure the economic impact of the policy of meat products in support of Iraq. Goods are both careless fish andBeef.

\subsection{State intervention in pricing of goods}

\section{Theoretical framework}

The aim of the intervention price policy is to achieve some of the economic, social and political objectives. Thus, the economic effects of which affect the level of production of a particular commodity to increase production. For example, by supporting the purchase of producer prices or reduce the input and output prices or impose a tax on the import of a particular commodity affect imports to the Treasury. On the other hand, the support price policy to benefit consumers by lowering the prices of consumer goods the state treasury and holds a price difference. It has made the price of the direct and indirect effects of the policy, both on the level of production or consumption, or the import of the Treasury Department, local or foreign currency, as well as exports and imports, and thus affects the performance efficiency of the country's economy toward a particular commodity.

Many developing countries rely government intervention in the pricing of agricultural and animal products. The major grains that were the backbone of food security in the countries that first crop were government interference in pricing. The main reasons to ensure the interests of producers, as well as providing food for people. Therefore, the economic and social logic behind state intervention in agricultural products pricing (immolated, 1999), which ensures that farmers get income bonus on the income earned by workers in other sectors of the economy, and protection from price fluctuations due to natural and economic factors and reduced flexibility supply and demand for agricultural products, and control over production, and its production plan in the future due to the uncertainty of living situation. Economists justify these reasons, state intervention in the pricing of agricultural commodities.

Despite to all positive reasons of state intervention in the pricing of goods and there are negative effects as a result of the indirect effects of some macroeconomic policies such as exchange rate policy. Iraq seemed to government pricing for some crops since the (1972) for the purpose of the product and consumer support either, but the experiment did not affect in stimulating crop producers to increase production due to the fact that there is a feeling among producers that the price set is not enough, and thus led to the poor response to these prices. In addition to the fact that the prices have an impact on the economic aspects, such as the well-being of producers and consumers, and the results of the state of revenue. In this research, you will discover the effects of the intervention prices for livestock products, fish and beef.

\subsection{Concept of Partial Equilibrium}

Partial equilibrium has to do with the price of any commodity policy. Partial equilibrium interested in my balance and single market analysis, both in all markets linked with each other to achieve the existence of possibilities in the production and consumption of various commodities. So must all analyzes that are connected in the prices of agricultural products in the framework of general equilibrium (full) where the results of any good or service depends on activities in all markets, and factors of production, and other products. For example, that if the price of a particular commodity, the change affects the overall balance must understand the relationship between the general equilibrium and partial equilibrium .l partial equilibrium analysis and consumer product access to the single market behavior $\mathrm{r}$. The overall balance represents the sum of the single market for goods. It must be a link between these two branches of the economy for the purpose of understanding the effects of changing prices between one market and know the importance Zubaie(1995). Analysis starts from simple to complex any of the Single Market Analysis (partial equilibrium) and when interpreting the model carefully and mastering it will provide the general trends for the rest of the other markets, for example, when they should study the market are three other commodity markets, a particular commodity diagnosed at least have a link with this item, the input market and the labor market and the market of alternative results. These markets will affect the shape of the support Item familiarize price, and it is not easy to effect multiple markets, even if the diagnosis is unclear due to the possibility of overlapping markets transitional effects.

\subsection{Transitional effects price policy}


The building analysis on the basis of a specimen balance is full for a particular product uses a productive particular in the production, for example, or compete with alternative crop, it will appear that the changes that occur in the market for this item will move to markets other commodities as markets the output element or replacement goods or foreign currency market. It's an additional analysis of the market or requires any more need for a specimen sector of the surround effects that may occur analysis, economic paradigm entirely to ensure consistency in all of the national income, trade and investment accounts, for example. As price changes that can occur for a good single or changes that occur at the same time for a number of commodities triggered transition is expected to claim the important goods (it was to be the main source of wages or income or on the external trade front) to the effects of sectorial and macroeconomic Timmer, (1986) .The most case difficult to analyze price policy when those goods are important both in terms of the level of use of food and the situation of the poor and the amount of foreign currency reserves at the price of my job, whether exported or imported associated. Temporal dimension of his importance in the analysis as well. After a long period of time passage starts adapt producers and consumers to price changes rather quickly.

\subsection{Direct economic impact for subsidy}

In order to have the domestic price which puts desirable to pay subsidies on imported from units equal to the difference between the border price and the domestic price commodity? State support paid for importers to cover the loss of import for the purpose of preventing the border that prevails in the local market price. It needs to source funding from the public treasury in order to make the domestic price lower than the price paid for the border to import basic goods. If the country is a source for this item, which aims to reduce domestic prices lower than world prices to any country of the importing country of the commodity, but in this case support the import tax on the export of any state treasury become you will get a revenue rather than spending. Other direct effects of subsidies also that consumer are responding to low-price increase consumption either producers to respond to low prices and the reduction of the quantities of goods produced with the rising costs. Support also lead to increased spending of foreign currency to buy imported goods. Impact on trade volume of domestic subsidized price leads through subsidies to increase the gap to import because of the participation of high demand and low supply, and the increasing need for imports, depending on the elasticity of supply and demand, for example, the changes will be in each of the large consumption if they responded local decisionmakers to completely flexible and import gap change much if the flexible non-existent. Also the impact of subsidies on the well-being of both producers and consumers at the same time through the prices of all of them experienced at the request of the local price policy of low commodity producers, consumer benefit on account of which should be another carry an implicit tax on the same amount of support from the consumers Zubaie (1995). It also can affect the price support in the level of economic performance by measuring the degree of efficiency in the use of resources through efficient allocation of resources, whether in production or consumption. We conclude that the effects of the price policy of directly and indirectly on the economic performance of any country should take into account by measuring and analyzing the work in practice. We, therefore, the economic impact of the pricing of meat fish and beef measure will (commodities research sample) and knowledge of these effects on both sides of production, consumption and Treasury yields for the purpose of drawing the pricing policy which aims to achieve well-being of both producers and consumers together.

\section{Measures usefor analysis}

Models must be interpreted carefully in order to provide clear directions to determine the direct effects in other markets because of the correlation between markets. Through the potential cost of various goods replaced. A set of criteria for the study and analysis of multiple effects on the single market. These represent metrics in the form of import duties on express or implied charge. The explicit support what you pay the amount from the state treasury to bridge the difference between the local price and the price the border, either implicit subsidies through the exchange rates, which act as a tax on the product.

\subsection{Changes in Government Revenue (GR)}

This measures the effect of price policy for a particular commodity in the returns obtained by the state either import or export increase or decrease. When a tax on exports, as well as when to impose import duties, the state returns in this case is positive and vice versa. Can be measured by the following relationship, Tskok(1991):

$$
\begin{aligned}
& \text { NPC-1 } \\
& \text { GR = - } \\
& \text { NPC }
\end{aligned}
$$

Where: NPC: Net Nominal Protection Coefficient, Vc: Consumption value domestic prices ,Vp: production value domestic prices. 


\subsection{Net Economic Loss in Consumption (NELC)}

This loss occurs is a loss in efficiency, because the consumer will convert part of the expenditure on consumer goods, which gets them on the benefits of the largest and most comprehensive benefits. This loss in efficiency or so-called net loss of production or consumption that occurs depending on the pattern of price policy is not utilized at the end of any of the product or the consumer as it cannot be any of the two groups that are adding to the their surplus (surplus producer and consumer surplus) and cannot be the state also add to the coffers. We can measure this loss as the following equations (Tsakok .1991; 188):The following equation is used in the event of a price intervention:

NPC-1

$\mathrm{NELC}=0.5 \mathrm{nd}(--\cdot-\cdot--\cdot----)^{2} \mathrm{Vc}$

NPC

nd : Price elasticity of demand for the commodity, rest of the symbols previously was known.

\subsection{Net Economic Loss in Production (NELP)}

This loss arises because of non-rational use of local resources for a particular commodity, leading to a loss in production and then a loss in efficiency. This is because the resources pulled toward the item or supplier backed away from goods that are high productivity. The cause of this loss in production efficiency loss in net economic output and prevents the development of its supplier's optimal combination of local resources to achieve the greatest possible profit. It can calculate the loss in net economic output in the following equations (Tsakok .1991; 188):

NELP $=0.5$ es $\left(-\begin{array}{c}\text { NPC-1 } \\ \text { NPC }\end{array}\right.$
es : Price elasticity of supply , rest of the symbols previously was known.

\subsection{Net Effect}

This measure defines the outcome of economic activities pertaining to the consumption and production of a particular commodity as well as a change in state revenues. It also defines as the net outcome of the economic losses in production and economic losses in net consumption, which represents in dead weight efficiency losses the cause of this loss in efficiency is the pattern of price policy followed towards a particular commodity. In addition, the net effect is an indication of the efficiency of the price policy and the extent of its success in achieving its objectives in the economic well-being (Hayali, 1997;133). We can measure the net effect to one of the following equations (Tsakok .1991; 189):

Net effect $=-($ NELP + NELC $)$

\subsection{Consumer Surplus (CS)}

This indicator reflects the effective price policy toward the consumer, whether an increase in consumer welfare or decrease. it will increase consumer welfare If pricing policy has been encouraging consumer and the opposite is true. It can measure change in consumer the following mathematical formula (Tsakok .1991; 189):

NPC - 1

CS = - [(-------- Vc) + NELC $]$

Where :NELC: Net Economic Loss in Consumption.

\subsection{Producer Surplus (PS)}

This indicator represents the welfare state product increase or decrease as a result of a policy of intervention price for a commodity. It may be an increase in the welfare of the product in the case of a policy of encouraging support price of the product; otherwise it can be a decrease in the welfare of the product. It can measure the change in producer surplus by using the following mathematical formula (Tsakok .1991; 189):

NPC - 1

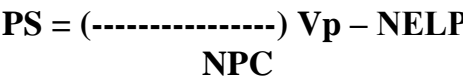

WhereNELP: Net Economic Loss in Production

\section{Results and discussion}

In this section we will show the results that have been reached. These results are based on data obtained previously and depending on mathematical formulas set out to achieve a measure impact of price policy towards meat in Iraq. The results that have been reached for each of the fish meat, as well as Beef during the period 
(1985-2013), which was calculated based on the data in the Appendix, where the data in Table 1 in Appendix to the production and consumption of each commodity careless values and characterized by values in general except for increasing duration of study for both commodities. Data in Table (2) in Appendix refers to the net nominal protection coefficients values for the two commodities. Results reached values significantly affected by those values as well as the elasticity of supply and demand for goods and based on previous equations in the research.

Results in Table (1) shows the values of the change in state revenues during the period of study for both commodities.Beef was positive results for each period due to the fact that the signal is positive values. In other words, it was the state provides revenue through pricing practice with Beef system. This indicates that the performance price policy was positive. Except years $(1991,1992,1994,1996)$, where the values of the change in state revenues is negative in the sense that the state was losing revenue from the treasury through the price policy for all those years. The results have been generally increasing, reaching (99.4) thousand dinars(ID) in 1985 even reached $(1,886,582.4)$ thousand dinars(ID) in 2010 and then took a drop, depending on the difference between the values of production and consumption of goods values.

About Fish was negative results for most of the period due to the fact that a negative signal values, especially the period (1987-1999) and (2011-2013). In other words, the state loses revenue from the treasury during practice with the Fish pricing system during those periods. This indicates that the performance price policy was negative. The rest of the years was a signal of change in state revenues was positive was the state provides any of those returns. Values the positive change in the fish characterized by fluctuating between increases and decreases during the period of the study until it reached a maximum in 2010 reached $(161,018.0)$ thousand dinars(ID). Depending on the values of both production and consumption. As well asobserve that the change in state revenue in the beefis greater than values in Fish.

Table (1) values of change in staterevenue $(\Delta \mathrm{GR})$ to Beef and fish in Iraq (1985 -2013) (000 ID)

\begin{tabular}{|c|c|c|}
\hline \multirow[t]{2}{*}{ Years } & \multicolumn{2}{|l|}{$\Delta \mathbf{G R}$} \\
\hline & Beef & Fish \\
\hline 1985 & 99.4 & 6.3 \\
\hline 1986 & 57.4 & 6.5 \\
\hline 1987 & 51.2 & -2.0 \\
\hline 1988 & 58.6 & -9.6 \\
\hline 1989 & 169.3 & -1.1 \\
\hline 1990 & 191.7 & -306.0 \\
\hline 1991 & -57.2 & -373.5 \\
\hline 1992 & -153.1 & -921.2 \\
\hline 1993 & 89.6 & -9446.1 \\
\hline 1994 & -17681.9 & -18349.0 \\
\hline 1995 & 695.5 & -51326.2 \\
\hline 1996 & -27177.2 & -10859.2 \\
\hline 1997 & 2811.3 & -8035.7 \\
\hline 1998 & 1445.5 & -23318.9 \\
\hline 1999 & 8012.9 & -40885.5 \\
\hline 2000 & 2170.9 & 1393.9 \\
\hline 2001 & 1319.9 & 3496.8 \\
\hline 2002 & 28488.0 & 79.5 \\
\hline 2003 & 77260.9 & 590.7 \\
\hline 2004 & 139180.6 & 1786.7 \\
\hline 2005 & 131290.2 & 2314.6 \\
\hline 2006 & 176472.2 & 3643.5 \\
\hline 2007 & 186521.6 & 6273.5 \\
\hline 2008 & 168794.3 & 37531.5 \\
\hline 2009 & 996953.3 & 60205.3 \\
\hline 2010 & 1886582.4 & 161018.0 \\
\hline 2011 & 967890.4 & -6771.5 \\
\hline 2012 & 1011241.2 & -78798.0 \\
\hline 2013 & 12550.4 & -152235.9 \\
\hline
\end{tabular}

Source: calculated depending on Tables $(1,2)$ in the Appendix

The value of the loss in both sides of the production and consumption As well as net effect values, which are also dependent on the values of production and consumption of goods studied, in addition to the price elasticity of supply and demand for both commodities, they can show in table (2). This table shows the net economic loss in production values and both commodities, these values are characterized by inequality and variation from year to year depending on the production and consumption values, depending on the flexibility of being used offer at this very study (1.3) (0.08) for fish and red meat, respectively. The highest amount reached to the values of production loss (95,088.71) thousand dinars(ID)in 1999 for fish and (39399.15) thousand 
dinars(ID) in 2010 for beef. The loss in production values also indicates the existence of a missing Lost in production efficiency of meat products. In general values of that loss were the biggest in fish. This table shows the net economic loss in the consumption values and both commodities as well, these values are characterized by inequality and variation from year to year, depending on consumption values and by the flexibility of being used demand in the adult study (0.33-), (0.18-) Fish and red meat, respectively. The highest amount reached to the values of the loss in consumption (38970.42) thousand dinars(ID) in 1995 to fish and $(209,465.22)$ thousand dinars(ID) in 2010 of red meat. Loss in the consumption values also indicates the existence of a missing Lost in efficient consumption of meat products through price policy. This table also shows the net effect of both values and commodities as well. This effect depends on the values of each of the losses in production and consumption. These values are characterized by inequality and variation from year to year. The net effect of all the values was negative and both commodities and refers to having lost in the exploitation of resources at the level of the country's economy for meat products through price policy followed during the study period.

Table (2) values of losses in both production (NELP), consumption (NELC) and Net Effect for meat in Iraq (1985 -2013) (000 ID)

\begin{tabular}{|c|c|c|c|c|c|c|}
\hline \multirow[t]{2}{*}{ Years } & \multicolumn{2}{|l|}{ NELP* } & \multicolumn{2}{|l|}{ NELC** } & \multicolumn{2}{|l|}{ Net Effect } \\
\hline & Beef & Fish & Beef & Fish & Beef & Fish \\
\hline 1985 & 0.53 & 3.40 & 3.20 & 1.06 & -3.72 & -4.46 \\
\hline 1986 & 0.77 & 3.78 & 3.08 & 1.16 & -3.85 & -4.94 \\
\hline 1987 & 0.40 & 0.11 & 1.70 & 0.04 & -2.10 & -0.15 \\
\hline 1988 & 0.10 & 0.55 & 0.71 & 0.30 & -0.80 & -0.86 \\
\hline 1989 & 2.09 & 0.05 & 9.74 & 0.02 & -11.83 & -0.07 \\
\hline 1990 & 3.35 & 28.12 & 14.27 & 39.23 & -17.61 & -67.36 \\
\hline 1991 & 4.80 & 458.83 & 13.02 & 267.82 & -17.82 & -726.65 \\
\hline 1992 & 18.84 & 798.85 & 49.01 & 490.31 & -67.84 & -1289.17 \\
\hline 1993 & 0.14 & 25035.13 & 0.49 & 16340.59 & -0.63 & -41375.72 \\
\hline 1994 & 15899.17 & 62521.71 & 41736.25 & 30537.81 & -57635.42 & -93059.53 \\
\hline 1995 & 3.15 & 84995.32 & 8.98 & 38970.42 & -12.13 & -123965.74 \\
\hline 1996 & 20969.80 & 8266.69 & 53648.75 & 3243.46 & -74618.55 & -11510.14 \\
\hline 1997 & 487.94 & 5282.46 & 1186.54 & 1907.27 & -1674.48 & -7189.72 \\
\hline 1998 & 1026.17 & 54615.25 & 2367.24 & 19209.13 & -3393.42 & -73824.38 \\
\hline 1999 & 820.70 & 95088.71 & 2130.06 & 36348.66 & -2950.76 & -131437.38 \\
\hline 2000 & 485.59 & 85.06 & 1224.38 & 33.50 & -1709.97 & -118.56 \\
\hline 2001 & 1293.76 & 2606.18 & 3197.78 & 823.32 & -4491.55 & -3429.50 \\
\hline 2002 & 1926.29 & 173.21 & 5309.65 & 44.66 & -7235.94 & -217.88 \\
\hline 2003 & 1810.38 & 515.27 & 6626.43 & 144.43 & -8436.81 & -659.71 \\
\hline 2004 & 6087.00 & 3338.84 & 21401.07 & 957.95 & -27488.07 & -4296.80 \\
\hline 2005 & 7207.95 & 3094.26 & 23390.46 & 885.48 & -30598.41 & -3979.74 \\
\hline 2006 & 8642.67 & 1080.63 & 29017.03 & 347.53 & -37659.71 & -1428.16 \\
\hline 2007 & 12435.65 & 14316.68 & 38978.84 & 4027.02 & -51414.49 & -18343.70 \\
\hline 2008 & 16762.96 & 24861.13 & 47879.89 & 9207.18 & -64642.86 & -34068.31 \\
\hline 2009 & 29486.30 & 30977.14 & 131781.69 & 12471.38 & -161267.99 & -43448.53 \\
\hline 2010 & 39399.15 & 51012.72 & 209465.22 & 25812.84 & -248864.38 & -76825.56 \\
\hline 2011 & 10802.92 & 157.41 & 55349.86 & 70.63 & -66152.78 & -228.04 \\
\hline 2012 & 4337.20 & 7558.38 & 29800.78 & 3937.93 & -34137.98 & -11496.32 \\
\hline 2013 & 396.54 & 42996.20 & 967.90 & 21336.41 & -1364.44 & -64332.62 \\
\hline
\end{tabular}

Source: calculated depending on Tables $(1,2)$ in the Appendix

* Supply elasticity used in the calculation Fish (1.3) Beef (0.08) (Ismail, 2001)

**Price elasticity of demand for fish meat used in the calculation (0.33-) (Jassim, 2010)

** Price elasticity of demand for meat Beef used in the calculation (0.18-)(Abdu Al-Salam ,2013)

The results of the change in the surplus of producers (PS) and consumers (CS). Table 3 shows the values of surpluses for both producer and consumer to the goods studied in Iraq for a period of study. The results of the change in consumer surplus (CS) for beef that the change in consumer surplus calculated values was negative for most of the years of study because of the negative signal change and this shows that there is a decrease in consumer welfare for most of the years of study of the beef product. Also said that the amounts of negative values of the change in consumer surplus was significantly increased during the period, reaching the highest amount of negative change $(3,480,304.53)$ thousand dinars in 2010, the year in which the highest amount of the loss occurred in the consumption of beef. Excluded from this years (1991, 1992, 1994.1996) was the change in the consumer surplus positively received by consumers during a period. This corresponds to the results of the rest of the other measurements that showed that the protection was for the benefit of producers and not consumers. On the results of fish that values calculated change in consumer surplus was positive during the period (1987-1992), (1994-1999) and (2011-2013) due to signal change was positive during those periods where 
increasing in welfare of consumers of fish meat. Also the values of the change in consumer surplus positive was significantly increased during the years mentioned previously, reaching a maximum of $(290,328.46)$ thousand dinars in 2013. About the change in consumer surplus for Fish negative in the years $(1985.1986,1993)$ and the period (2000-2010) and was the highest adverse change $(348,924.32)$ thousand dinars in 2010, where there was a shortage in the welfare of the consumers of fish during the period.

The results of the change in producer surplus (PS)When the note values shown in Table 3 we find that the welfare of the product has increased in most years since that signal a change in the product surplus came positive refers to the increase in the surplus of the product and well-being for beef. That means the price policy of the state was in favor of the producers of any reverse the results of the change in consumer surplus. Also it increased the amounts during the period until the highest value reached a positive $(1,344,857.73)$ thousand dinars in 2010. Also it excludes years $(1991,1992,1994.1996)$, which was a decrease in the surplus of the product because of the negative values of any change that during those years did not get an increase in the welfare of producers during the period of the study. As for the results of surplus producers of fish and this is also confirmed by what has been reached from the results when measuring the average nominal protection coefficient, since the results of the laboratory showed that the state was conducive for the product and for most of the years of study. As for the results of surplus producers of fish welfare of the product has increased for years $(1985,1986)$ and the period $(2000-2010)$ as the signal change in the product surplus came positive refers to the increase in the surplus of the product and well-being for your name. That means the price policy of the state was in favor of the producers. Also it increased the amounts of these amounts during the period until the highest value reached a positive change $(111,080.79)$ thousand dinars in 2010. For the period (1987-1999) and the period (2011-2013) which was a decrease in the surplus of the product because of the negative values of any change that during those years did not get an increase in the welfare of producers during the period of study and reached the highest negative change in the welfare of producers Fish $(202,425.13)$ thousand dinars in 2013. Results also reflected the change in the consumer surplus except in 1993 which it did not get the welfare not for the benefit of producers and consumers.

Table: (3)values of surpluses for both producer and consumer to meat in Iraq (1985 -2013) (000 ID)

\begin{tabular}{|c|c|c|c|c|}
\hline \multirow[t]{2}{*}{ Years } & \multicolumn{2}{|l|}{ PS } & \multicolumn{2}{|l|}{ CS } \\
\hline & Beef & Fish & Beef & Fish \\
\hline 1985 & 58.12 & 24.10 & -161.25 & -34.87 \\
\hline 1986 & 74.27 & 27.48 & -135.54 & -38.96 \\
\hline 1987 & 56.06 & -3.50 & -109.38 & 5.34 \\
\hline 1988 & 26.08 & -8.84 & -85.51 & 17.60 \\
\hline 1989 & 155.32 & -2.47 & -336.47 & 3.46 \\
\hline 1990 & 210.78 & -96.19 & -420.07 & 334.88 \\
\hline 1991 & -282.63 & -746.21 & 322.04 & 393.01 \\
\hline 1992 & -997.96 & -1448.54 & 1083.20 & 1080.55 \\
\hline 1993 & 154.06 & -31046.87 & -244.32 & -882.78 \\
\hline 1994 & -121973.86 & -82376.92 & 82020.34 & 7666.37 \\
\hline 1995 & 2622.45 & -148658.46 & -3330.06 & 76018.91 \\
\hline 1996 & -219258.40 & -28168.74 & 171817.02 & 27517.81 \\
\hline 1997 & 34312.91 & -24308.89 & -38798.69 & 25154.86 \\
\hline 1998 & 56165.83 & -115097.10 & -61004.73 & 64591.66 \\
\hline 1999 & 51374.52 & -175910.03 & -62338.13 & 85358.13 \\
\hline 2000 & 41818.45 & 2443.06 & -48632.05 & -3955.47 \\
\hline 2001 & 73250.99 & 11695.69 & -85087.43 & -18621.98 \\
\hline 2002 & 124645.79 & 4850.03 & -160369.73 & -5147.38 \\
\hline 2003 & 121456.50 & 5151.53 & -207154.22 & -6401.89 \\
\hline 2004 & 241298.03 & 10377.97 & -407966.71 & -16461.46 \\
\hline 2005 & 289652.44 & 15083.24 & -451541.09 & -21377.54 \\
\hline 2006 & 349906.78 & 12569.99 & -564038.71 & -17641.68 \\
\hline 2007 & 462070.07 & 43728.20 & -700006.17 & -68345.36 \\
\hline 2008 & 609648.28 & 56918.98 & -843085.45 & -128518.83 \\
\hline 2009 & 981280.06 & 71762.52 & -2139501.36 & -175416.31 \\
\hline 2010 & 1344857.73 & 111080.79 & -3480304.53 & -348924.32 \\
\hline 2011 & 747044.62 & -8979.09 & -1781087.76 & 15522.56 \\
\hline 2012 & 488045.93 & -82430.81 & -1533425.11 & 149732.54 \\
\hline 2013 & 147573.41 & -202425.13 & -161488.26 & 290328.46 \\
\hline
\end{tabular}

Source: calculated depending on the results in the table (2) and Data Table 1 inthe Appendix

\section{Conclusion}

There is a clear difference in the effects of commodity prices, a policy studied during the period of study. The effects of different price policy towards each commodity separately, be linked to price policy and other policies with each other and are affected by the price of the terms of indicators. The development of 
political, economic and social country. Reached vary depending on the type of commodities, and the time period in addition to the impact of the results of all the data. Some of the results of these negative indicators, for example, there was a loss of production and consumption efficiency, and some of them were positive for commodities, we find that encouraging price to producers of beef policy, as well as providing excessive support them more than consumers who do not have access to protection this explains the problem of bovine meat prices increased significantly during the study period as consumers hurt because of it. As for the fish was not a specific policy to protect the pair to producers or consumers volatile favor producers in some years and in favor of consumers through more than a year. It should reconsider some of the negative effects that occur in some aspects of pricing policies for different commodities. It can other commodities are studies in the future in order to diagnose the potential negative impacts that occur.

\section{References}

[1]. Mudhi, A. Ali (1999) The Consequences of the price policy toward some major cereal crops in Iraq, the Iraqi Journal of Agricultural Science, Volume 30, Issue 2 p533.

[2]. Timmer,C.P. (1986), Getting Prices Right,Cornell University Press Ithaca and London, p32,33.

[3]. Zobaie, A. A. (1995). An economic analysis of the implications of supporting the prices of major cereal crops in Iraq for the period (1970-1990). Wheat specimen applied - doctoral thesis - Agricultural economics, University of Baghdad, College of Agriculture, Iraq.

[4]. Tskok(1991), I.Agriculturalprjcepoljcy , cornel University press, Ithaca and London , p188

[5]. Ismail O.Hammadi (2001) structural developments in the agricultural sector, economic studies (price elasticities of supply of agricultural products, the researchers set the House of Wisdom of Baghdad ,Iraq.

[6]. Jassim M. Habib and others (2010) economic analysis to the factors affecting required of fish meat in Iraq for the period quantities (1980-2002), Journal of the Faculty of Management and Economics, Mustansiriya University,No.81 Baghdad, Iraq.

[7]. Abd Al-Salam M. Hussein (2013) Economic Analysis of the Variations in the Local Production and theDemand on the Red Meat in Iraq for the Period (1985- 2006). Rafidain Development Journal vol 35 Issue 113. Iraq.

[8]. Hayali, A. D. Kiesar, (1997) Some of the considerations to be taken into account to draw rice price policy in Iraq, Master Thesis, University of Baghdad, College of Agriculture, Department of Agricultural Economics.Iraq

[9]. Tolly, G.S. (1982). Agricultural price policies and the developing countries, World bank Publication p.139

[10]. Mahjob, A. B. Ibrahim, (2000) The economic impact of the price policy for wheat crop in the Sudan for the period (1980 - 1997), (Al-Gezira project) model applied, Master Thesis, Agricultural Economics. College of Agriculture, University of Baghdad, Iraq

[11]. Mohammed A. K. Manhal,(2008). Domestic support policies in the agricultural sector in the Republic of Iraq ((before joining the World Trade Organization WTO)), country study, the Ministry of Agriculture of the Republic of Iraq.

[12]. Krueger,A.O,et . al.,(1991), The political economy of Agricultural Pricing Policy,vol.3 Africa and the Mediterranean ,A word Bank Publication, Washington.

[13]. J.Harrigan, et al. 1992, Agricultural Price Policy, FAO, Rome.

[14]. Eric Icart\& James N. Trapp (1999), AGRICULTURAL AND FOOD PRICE POLICY IN HAITI. Journal of Social and Economic Studies, University of the West Indies.Vol. 48, No. 3.

[15]. Norsida M., Sarmad A. \& others (2015). THE ECONOMIC EFFECTS OF NET NOMINAL PROTECTION COEFFICIENTS FOR MEAT PRODUCTS IN IRAQ. ARPN Journal of Agricultural and Biological Science .VOL. 10, NO.12, December.

\section{Appendix}

Tubal (1) Value of Consumptions, Value of productions to the Beef and fish in Iraq (1985 -2013) (000 ID)

\begin{tabular}{|c|c|c|c|c|}
\hline \multirow[t]{2}{*}{ Years } & \multicolumn{2}{|c|}{ Value of Consumptions } & \multicolumn{2}{|c|}{ Value of production } \\
\hline & Beef & Fish & Beef & Fish \\
\hline 1985 & 703.36 & 177.6 & 261 & 144.48 \\
\hline 1986 & 513.4684 & 203.154 & 290.88 & 168 \\
\hline 1987 & 612.3 & 108 & 321.03 & 68 \\
\hline 1988 & 916.3206 & 174.2 & 282.9 & 80.6 \\
\hline 1989 & 985.936 & 105.8 & 475 & 73.6 \\
\hline 1990 & 1038.7574 & 588.618 & 548.1 & 107.1 \\
\hline 1991 & 776.064 & 269.04 & 643.5 & 117 \\
\hline 1992 & 2354.1124 & 830.4 & 2035.82 & 343.44 \\
\hline 1993 & 10888.4 & 2412.75 & 6885.93 & 938.35 \\
\hline 1994 & 33026.7405 & 7886.2 & 28308 & 4098.56 \\
\hline 1995 & 110585.7 & 55984 & 87427.6 & 30995.2 \\
\hline 1996 & 85279.398 & 48137.55 & 75000 & 31144.23 \\
\hline 1997 & 107304 & 63357.3 & 99283.6 & 44544.3 \\
\hline 1998 & 130722.468 & 60321.55 & 127500 & 43536.09 \\
\hline 1999 & 153165.135 & 67239.6 & 132781 & 44651.52 \\
\hline 2000 & 165205 & 75768 & 157640 & 48840.4 \\
\hline 2001 & 188734.61 & 63487.6 & 185692.5 & 51014.6 \\
\hline 2002 & 407545.88 & 96188.04 & 332670.6 & 94690.05 \\
\hline 2003 & 546150 & 44731.25 & 335725.07 & 40509 \\
\hline 2004 & 628425 & 41400 & 402164.4 & 36628.88 \\
\hline 2005 & 705337.5 & 78248.5 & 489049.29 & 69410.41 \\
\hline 2006 & 887835 & 142000 & 594990.39 & 112083.44 \\
\hline 2007 & 1008910 & 169500 & 724226.58 & 152967.36 \\
\hline 2008 & 1188634 & 255107.4 & 936328.59 & 174858.95 \\
\hline 2009 & 2752920 & 351278 & 1385930 & 221487 \\
\hline
\end{tabular}




\begin{tabular}{|l|l|l|l|l|}
\hline 2010 & 4596730 & 667348.8 & 1945389.1 & 334785.1 \\
\hline 2011 & 4842567 & 568014.85 & 2126584.5 & 321348 \\
\hline 2012 & 6828000 & 989456.4 & 2235925.5 & 482090 \\
\hline 2013 & 2395927.5 & 751170 & 2208600.1 & 384253.2 \\
\hline
\end{tabular}

Source: Ministry of Planning, the Central Bureau of Statistics (NBS), the Department of National Accounts, commodity balances for the years (1985 -2013)

Table (2) Values of Net nominal protection coefficients (NPC) for Beef and Fish meat in Iraq (1985 -2013)

\begin{tabular}{|c|c|c|}
\hline \multirow[t]{2}{*}{ Years } & \multicolumn{2}{|l|}{ NPC } \\
\hline & Beef & Fish \\
\hline 1985 & 1.290 & 1.235 \\
\hline 1986 & 1.348 & 1.229 \\
\hline 1987 & 1.213 & 0.952 \\
\hline 1988 & 1.102 & 0.907 \\
\hline 1989 & 1.496 & 0.968 \\
\hline 1990 & 1.641 & 0.611 \\
\hline 1991 & 0.698 & 0.289 \\
\hline 1992 & 0.675 & 0.346 \\
\hline 1993 & 1.023 & 0.135 \\
\hline 1994 & 0.211 & 0.171 \\
\hline 1995 & 1.031 & 0.327 \\
\hline 1996 & 0.274 & 0.610 \\
\hline 1997 & 1.540 & 0.701 \\
\hline 1998 & 1.813 & 0.419 \\
\hline 1999 & 1.648 & 0.356 \\
\hline 2000 & 1.402 & 1.055 \\
\hline 2001 & 1.766 & 1.390 \\
\hline 2002 & 1.614 & 1.056 \\
\hline 2003 & 1.580 & 1.163 \\
\hline 2004 & 2.598 & 1.599 \\
\hline 2005 & 2.545 & 1.355 \\
\hline 2006 & 2.516 & 1.139 \\
\hline 2007 & 2.900 & 1.611 \\
\hline 2008 & 3.021 & 1.879 \\
\hline 2009 & 3.694 & 1.865 \\
\hline 2010 & 3.467 & 1.939 \\
\hline 2011 & 1.554 & 0.973 \\
\hline 2012 & 1.282 & 0.866 \\
\hline 2013 & 1.072 & 0.707 \\
\hline
\end{tabular}

Source: Norsida M., Sarmad A. \& others (2015).THE ECONOMIC EFFECTS OF NET NOMINAL PROTECTION COEFFICIENTS FOR MEAT PRODUCTS IN IRAQ. ARPN Journal of Agricultural and Biological Science .VOL. 10, NO.12, December. 